\title{
Optimum Conditions and LC-ESI-MS Analysis of Phenolic Rich Extract from Eucalyptus marginata L. under Maceration and Ultrasound-Assisted Extraction Methods Using Response Surface Methodology
}

\author{
Soumaya Hasni $\mathbb{D}^{1},{ }^{1}$ Ghayth Rigane $\mathbb{D}$, ${ }^{1,2}$ Hanene Ghazghazi $\mathbb{D}^{3},{ }^{3}$ Hajer Riguene, ${ }^{1}$ \\ Amir Bouallegue $\mathbb{D}^{4},{ }^{4}$ Olfa Khedher, ${ }^{1}$ Moufida A. Oueslati $\mathbb{D},{ }^{5}$ and Ridha Ben Salem $\mathbb{D}^{1}$ \\ ${ }^{1}$ Laboratory of Organic Chemistry LR17ES08, Sciences Faculty of Sfax, B.P 1171, University of Sfax, Sfax 3038, Tunisia \\ ${ }^{2}$ Physic and Chemistry Department, Faculty of Sciences and Technology of Sidi Bouzid, B.P «380» 9100, Sidi Bouzid, \\ University of Kairouan, Kairouan, Tunisia \\ ${ }^{3}$ Laboratory of Management and Valorization of Forest Resources, National Research Institute of Rural Engineering, \\ Water and Forestry (INRGREF), Kairouan, Tunisia \\ ${ }^{4}$ Laboratory for the Improvement of Plants and Valorization of Agro-Ressources, National School of Engineering of Sfax (ENIS), \\ University of Sfax, Sfax 3038, Tunisia \\ ${ }^{5}$ College of Applied Medical Sciences Al Jubail, \\ Deanship of Preparatory Year and Supporting Studies and the Department of Respiratory Care, \\ Imam Abdulrahman Bin Faisal University, PO. Box 1982, Dammam 31441, Saudi Arabia
}

Correspondence should be addressed to Ghayth Rigane; gaith.rigane@yahoo.fr

Received 28 May 2021; Revised 1 October 2021; Accepted 20 October 2021; Published 8 November 2021

Academic Editor: Marcio Carocho

Copyright (c) 2021 Soumaya Hasni et al. This is an open access article distributed under the Creative Commons Attribution License, which permits unrestricted use, distribution, and reproduction in any medium, provided the original work is properly cited.

Eucalyptus marginata L. has a significant value in traditional medicine and recently has been shown to possess many pharmacological properties in vitro. The main goal of the present study was to optimize the extraction parameters of phenolic compounds from Eucalyptus marginata L. leaves using the extraction technique assisted by ultrasound in comparison with maceration using response surface methodology as a predicted tool. Therefore, total phenolic and flavonoid contents have been optimized, taking into account four variables: extraction time, temperature, liquid-to-solid ratio, and ethanol concentration. The optimum ultrasound-assisted extraction method for total phenolic and total flavonoid contents was obtained by ensuring the following parameters: $t=49.9 \mathrm{~min}, T=74.9^{\circ} \mathrm{C}$, liquid-to-solid ratio $=39.5 \mathrm{ml} / \mathrm{g}$, and ethanol $=58.48 \%$. The optimum extract has been subjected to LC-ESI-MS analysis. This technique allowed us to identify ten phenolic compounds: four phenolic acids mainly gallic acid $(27.77 \pm 0.06 \mu \mathrm{g} / \mathrm{g} \mathrm{DW})$ and protocatechuic acid $(37.66 \pm 0.04 \mu \mathrm{g} / \mathrm{g} \mathrm{DW})$ and six flavonoid compounds such as quercetrin $(150.78 \pm 0.02 \mu \mathrm{g} / \mathrm{g} \mathrm{DW})$ and hyperoside $(39.19 \pm 0.03 \mu \mathrm{g} / \mathrm{g} \mathrm{DW})$. These green and efficient procedures should be a promising option to guide industrial design for the production of phenolic-rich plant extracts.

\section{Introduction}

The Myrtaceae is a large evergreen tree that is known in the literature scientific with many synonyms including Calyptranthes oneilli Lundell, Calyptranthes jombolona Wild, and Eugenia cumini Druce. It contains around 3000 species such as Eucalyptus. It is a big and strong tree belonging to the family; however, some species are now distributed all over the world. It represents about $27 \%$ of the total timber volume and is one of the most important. Eucalyptus marginata is easily recognized by its flowers and fruits. Many research studies showed that the antioxidant activity, which is 
generally attributed with the interesting phenolic composition, allows this plant to be widely used in food and pharmaceutical industries [1-7]. Previous work showed that Eucalyptus is like any medicinal plant present an original chemical composition. Each organ apart has properties important because it contains essential oil and phenolic compounds as phenolic acids, flavonoids, and tannins. The composition makes the plant more magnificent and presents itself as a natural treasure since it is used in various fields, mainly the field of medicine $[1,3]$. Nowadays, nothing describes the particularity of Eucalyptus more clearly than the nature of its essential oil and phenolic composition, which is now very popular with the general public who aspires to treat themselves effectively with simple and natural means and which are designated for interesting biological and physiological purposes and activities. Indeed, many research studies' team showed that Eucalyptus marginata L. presents several properties of antioxidant, antimicrobial, anticancer, anti-inflammatory, and antifungal. In addition, it is designed for relaxation, mood disorders, and to relieve fever, coughs, and respiratory problems, even for the treatment of acne all by reducing the production of sebum [3]. Ultrasound-assisted extraction is a new technology used in several fields such as cosmetics, pharmaceutical, chemical, and food industries. Furthermore, Saifullah et al. [8] and Ezzoubi et al. [9] mentioned that ultrasound extraction allowed them to get extracts rich in biomolecules in a shorter extraction time with comparison to conventional extraction techniques. In addition, Chemat et al. [10] showed that the carvone yield extracted from Carum carvi L. seeds was higher using ultrasound treatment than those obtained using Soxhlet. A comparative study has been done by [11] who studied the extraction of phenolic compounds yields from Acacia confusa using ultrasound, maceration, and extraction assisted by heat. They confirmed that ultrasound treatment is the most fast and efficient technique, which allows to significantly increase the rate of phenolic content compared to other methods studied.

The aim of this work was to maximize the obtained total phenolic and flavonoid contents extracted from Eucalyptus marginata L. using ultrasound and maceration methods. In order to achieve this objective, we used the Box-Behnken design in conjunction with a response surface methodology (RSM) to optimizing four parameters: the extraction time $(\mathrm{min})$, temperature $\left({ }^{\circ} \mathrm{C}\right)$, liquidto-solid ratio $(\mathrm{ml} / \mathrm{g})$, and ethanol concentration (\%). In addition, the individual phenolic compounds present in the optimum extraction condition have been identified and quantified using LC-ESI-MS.

\section{Materials and Methods}

2.1. Plant Material and Sample Preparation. Eucalyptus marginata L. leaves were collected in January 2020, from Souiniet arboreta from northeastern provinces of Tunisia $\left(35^{\circ} 54 \mathrm{~N}\right.$ and $\left.8^{\circ} 48 \mathrm{E}, 492 \mathrm{~m}\right)$ under semiarid bioclimate. A voucher specimen of Eucalyptus marginata L. (LGVR 2020) was deposited at the Laboratory of Organic Chemistry LR17ES08, Faculty of Sciences of Sfax, University of Sfax,
Tunisia. Only healthy leaves have been harvested at different heights and immediately transported to our laboratory. In the same day, leaves were all ground using an electric mill (Retsch Muhle, Grindomix, GM200, Kurt Retsch GmbH and Co., KG, Haan, Germany), at a speed of $10000 \mathrm{rpm} / \mathrm{min}$, using a $0.5 \mathrm{~mm}$ mesh screen to improve contact with the solvent.

\subsection{Maceration and Ultrasound-Assisted Extraction}

2.2.1. Maceration Extraction. Briefly, twenty grams of Eucalyptus marginata leaves powders were extracted by maceration according to experimental design and under continuous agitation using a magnetic laboratory shaker TTSSMS-200, TT-DMS series with $1800 \mathrm{rpm}\left(11310 \mathrm{rad} \mathrm{min}^{-1}\right)$ (Table 1).

2.2.2. Ultrasound-Assisted Extraction. The extraction method was performed using an Elmasonic S60H ultrasonic bath (Elma Hans Schmidbauer GmbH and Co., Singen. Germany) [12]. The Eucalyptus marginata L. leaves powders' $(2.5 \mathrm{~g})$ was placed in a beaker $(100 \mathrm{ml})$ and mixed with an appropriate amount of the extraction solution (according to experimental design) (Table 1). The beaker with the suspension was immersed in water in the ultrasonic device and irradiated for the preset extraction time.

For both extraction methods, the resulting extract was then filtered through Whatman no. 4 paper and evaporated under vacuum at $40^{\circ} \mathrm{C}$ on a rotary evaporator until dryness. Each sample was kept in the refrigerator at $+4^{\circ} \mathrm{C}$ until use. Experiments were performed in triplicate (Table 1). Each extractions method was replicated three times.

2.3. Experimental Design. Response surface methodology (RSM) was used for investigating the influence of four independent variables on total phenolic and flavonoid content in Eucalyptus marginata L. leaves extracts [13]. The extraction time (min, $\left.X_{1}\right)$, temperature $\left({ }^{\circ} \mathrm{C}, X_{2}\right)$, liquid-to-solid ratio $\left(\mathrm{ml} / \mathrm{g}, X_{3}\right)$, and ethanol concentration $\left(\%, X_{4}\right)$ were selected as independent variables that should be optimized for the extraction. The samples were kept at room temperature to avoid the degradation of temperature-sensitive compounds. In the study, the experiments were performed on the central composite design (CCD). The level values of the experimental factors are given in Tables 1 and 2 .

2.4. Total Phenols and Flavonoids Contents. Total phenol content was evaluated according to the Folin-Ciocalteu method according to Khedher et al. [5] with slight modification using a UV-visible spectrophotometer (Beckman DU 800). Total phenol content was calculated based on a gallic acid calibration curve $\left(R^{2}=0.9978\right)$ and expressed as $\mathrm{mg}$ gallic acid equivalent (GAE)/g dry weight (DW). In addition, total flavonoids content was estimated as reported previously by Ben Hmed et al. [6]. The total flavonoids content was quantified using quercetin standard curve 
TABLE 1: The operating conditions according to an experiment plan.

\begin{tabular}{|c|c|c|c|c|c|}
\hline$N$ & $X_{1} \operatorname{ME} t(\min )$ & $\mathrm{X}_{1} \mathrm{UAE} t(\mathrm{~min})$ & $X_{2} \mathrm{~T}\left({ }^{\circ} \mathrm{C}\right)$ & $X_{3} \mathrm{R}(\mathrm{ml} / \mathrm{g})$ & $X_{4}$ ethanol (\%) \\
\hline 1 & 30 & 10 & 25 & 20 & 20 \\
\hline 2 & 30 & 10 & 25 & 20 & 60 \\
\hline 3 & 30 & 10 & 25 & 40 & 20 \\
\hline 4 & 30 & 10 & 25 & 40 & 60 \\
\hline 5 & 30 & 10 & 75 & 20 & 20 \\
\hline 6 & 30 & 10 & 75 & 20 & 60 \\
\hline 7 & 30 & 10 & 75 & 40 & 20 \\
\hline 8 & 30 & 10 & 75 & 40 & 60 \\
\hline 9 & 90 & 50 & 25 & 20 & 20 \\
\hline 10 & 90 & 50 & 25 & 20 & 60 \\
\hline 11 & 90 & 50 & 25 & 40 & 20 \\
\hline 12 & 90 & 50 & 25 & 40 & 60 \\
\hline 13 & 90 & 50 & 75 & 20 & 20 \\
\hline 14 & 90 & 50 & 75 & 20 & 60 \\
\hline 15 & 90 & 50 & 75 & 40 & 20 \\
\hline 16 & 90 & 50 & 75 & 40 & 60 \\
\hline 17 & 60 & 30 & 50 & 30 & 40 \\
\hline 18 & 60 & 30 & 50 & 30 & 40 \\
\hline 19 & 60 & 30 & 50 & 30 & 40 \\
\hline 20 & 17.58 & 17.2 & 50 & 30 & 40 \\
\hline 21 & 102.42 & 58.2 & 50 & 30 & 40 \\
\hline 22 & 60 & 30 & 14.65 & 30 & 40 \\
\hline 23 & 60 & 30 & 85.35 & 30 & 40 \\
\hline 24 & 60 & 30 & 50 & 15.9 & 40 \\
\hline 25 & 60 & 30 & 50 & 44.1 & 40 \\
\hline 26 & 60 & 30 & 50 & 30 & 16.56 \\
\hline 27 & 60 & 30 & 50 & 30 & 96.56 \\
\hline
\end{tabular}

$\mathrm{ME}$, maceration extraction; UAE, ultrasound-assisted extraction; $t$, extraction time expressed in min; T, temperature expressed in ${ }^{\circ} \mathrm{C} ; \mathrm{R}$, solvent-solid ratio expressed in $\mathrm{mg} / \mathrm{g}$.

TABLE 2: The selected factors and their levels in the CCD design.

\begin{tabular}{ccccccc}
\hline & \multirow{2}{*}{ Factors } & \multirow{2}{*}{ Unit } & \multirow{3}{*}{ Symbol } & \multicolumn{4}{c}{ Factor levels } \\
& & & & -1 & 0 & 1 \\
\hline \multirow{4}{*}{$\mathrm{ME} \quad$} & Extraction time & $\min$ & $X_{1}$ & 30 & 60 & 90 \\
& Temperature & ${ }^{\circ} \mathrm{C}$ & $X_{2}$ & 25 & 50 & 75 \\
& Solvent-to-material ratio & $\mathrm{ml} / \mathrm{g}$ & $X_{3}$ & 20 & 30 & 40 \\
& Ethanol & $\%$ & $X_{4}$ & 20 & 40 & 60 \\
& Extraction time & $\mathrm{min}$ & $X_{1}$ & 10 & 30 & 60 \\
\multirow{2}{*}{ UAM } & Temperature & ${ }^{\circ} \mathrm{C}$ & $X_{2}$ & 20 & 50 & 75 \\
& Solvent-to-material ratio & $\mathrm{ml} / \mathrm{g}$ & $X_{3}$ & 20 & 30 & 40 \\
& Ethanol & $\%$ & $X_{4}$ & 20 & 40 & 60 \\
\hline
\end{tabular}

ME, maceration extraction; UAM, ultrasound-assisted extraction.

$\left(R^{2}=0.9954\right)$ and expressed as milligram of quercetin equivalent $(\mathrm{QE}) / \mathrm{g} \mathrm{DW}$.

2.5. LC-ESI-MS Analysis. The LC-ESI-MS analysis was carried out using a LC-electrospray ionization-tandem mass spectrometry (Shimadzu, Kyoto, Japan) equipped with electrospray ionization (ESI). An Aquasil C18 column (Thermo Electron, Dreieich, Germany) $(150 \mathrm{~mm} \times 3 \mathrm{~mm} \times 3 \mu \mathrm{m})$ proceeded by an Aquasil C18 guard column $(10 \mathrm{~mm} \times 3 \mathrm{~mm}, 3 \mu \mathrm{m}$, Thermo Electron $)$ were used for the analysis. The mobile phase was $\mathrm{A}(0.1 \%$ formic acid in $\left.\mathrm{H}_{2} \mathrm{O}, \mathrm{v} / \mathrm{v}\right)$ and $\mathrm{B}$ (0.1\% formic acid in methanol, v/v) with a linear gradient elution: $0-45 \mathrm{~min}, 10-100 \% \mathrm{~B}$;
45-55 min, $100 \%$ B. Reequilibration duration was 5 min between individual runs. The column temperature was maintained at $40^{\circ} \mathrm{C}$, the mobile phase flow rate was $0.4 \mathrm{ml} /$ min, and the injection volume was $5 \mu \mathrm{l}$. The mass spectrometer was operated in the negative ion mode with a capillary voltage of $-3.5 \mathrm{~V}$, nebulizing gas flow of $1.5 \mathrm{~L} / \mathrm{min}$, a dry gas flow rate of $12 \mathrm{~L} / \mathrm{min}$, a block source temperature of $400^{\circ} \mathrm{C}$, a DL (dissolving line) temperature of $250^{\circ} \mathrm{C}$, the full scan spectra from 50 to $2000 \mathrm{Da}$, and the negative ionization mode source voltage of $-4500 \mathrm{~V}$. The quantification of phenolic compounds was performed at 280 and $335 \mathrm{~nm}$ using four-point regression curve $\left(R^{2}=0.989\right)$ standards [7].

2.6. Software. NemrodW 2007 software has been used in order to build the experimental designs and regression analysis of the experimental data.

\section{Results and Discussion}

To find the conditions, which increase the extraction of phenolic compounds from Eucalyptus marginata leaves using maceration and ultrasound-assisted methods. It was very important to take into account the variables that affect the system behavior. Therefore, preliminary tests were reviewed individually to determine their experimental domain in order to obtain an appropriate RSM design by analyzing their general model responses. 


\subsection{Preliminary Study of Single Factor Experiments for Maceration and Ultrasound Extraction Methods}

3.1.1. Influence of Extraction Time. The extraction time is an important parameter to minimize the energy and the cost of the extraction process $[14,15]$. Therefore, extraction time has been ranged from 30 to $105 \mathrm{~min}$ for maceration and from 10 to 60 for ultrasound-assisted extraction methods. As shown in Figure 1(a) and Figure 2(a), we could note that the maximum TPC has been showed at $60 \mathrm{~min}$ and $30 \mathrm{~min}$ of extraction for maceration and ultrasound extraction, respectively (147.18 and $209.15 \mathrm{mg} \mathrm{GAE} / \mathrm{g}$ of DW, respectively). In addition, extraction time $>60$ and $>30 \mathrm{~min}$ for the both extraction methods decreased not only TPC but also TFC (Figure 1(a) and Figure 2(a)). The obtained results were in agreement with those reported by Khedher et al. [5] who showed that the highest TPC ( $332.55 \mathrm{mg} \mathrm{GAE} / \mathrm{g}$ DW) has been obtained for a period of extraction $t=60 \mathrm{~min}$. The last results were also in accordance to those reported by Ghafoor et al. [16], Alu'datt et al. [17], Rubio-Senent et al. [18], and Fan et al. [19] who claimed that longer extraction time of alperujo under hydrothermal conditions could provoke degradation or polymerization reactions of the phenolic extract and longer extraction times increased total phenolic content but reduced antioxidant activity and also caused the oxidation of the targeted compounds, mainly flavonoids.

3.1.2. Influence of Temperature. The solubility of phenolic compounds increased with increasing temperature used for extraction because the rise in temperature allows mass transfer easily between solvent and solid matter [17]. As indicated in Figure 1(b) and Figure 2(b), temperature extraction influenced significantly $(p<0.05)$ the TPC and TFC contents; for maceration and ultrasound extraction methods, our research team showed the highest TPC at $50^{\circ} \mathrm{C}$ (147.18 and $209.15 \mathrm{mg} \mathrm{GAE} / \mathrm{g} \mathrm{DW}$, respectively). On the other hand, using temperature $>50^{\circ} \mathrm{C}$ decreased significantly $(p<0.05)$ the TPC and TFC $(\sim 100-160 \mathrm{mg} \mathrm{GAE} / \mathrm{g}$ DW and $\sim 30-50 \mathrm{mg}$ QE/g DW, respectively) for the both studied extraction methods. By comparing the obtained results to those reported in the literature, it can be concluded that the temperature is an important factor to have a large part of the phenolic content; however, these compounds were sensitive to heat; it is estimated that the increase in the extraction temperature causes the decrease essentially when the temperature exceeds the boiling point of the solvent. This will be evaporated in the air which causes the reduction in volume which destroys the extraction efficiency $[20,21]$, Samaram et al., 2015 [23-25].

3.1.3. Influence of Liquid-to-Solid Ratio. The liquid-to-solid ratio plays an essential role in the extraction influencing the recovery of phenolic compounds. Indeed, its role behaves in improving the extraction yield because it influences the concentration gradient between the plant and the solvent which ensures the transfer of material as it is cited in the literature [26]. Therefore, to study the effect of different liquid-solid ratios on the extraction of phenolic compound from Eucalyptus marginata leaves, a different liquid-to-solid ratio $R$ varied from 15 to $40 \mathrm{ml} / \mathrm{g}$. Figure 1 (c) and Figure 2(c) show that the highest values of TPC and TFC were obtained for $30 \mathrm{ml} / \mathrm{g}$ : $147.18 \mathrm{mg} \mathrm{GAE} / \mathrm{g}$ DW and $49.75 \mathrm{mg} \mathrm{QE} / \mathrm{g} \mathrm{DW}$ for the maceration extraction method and $209.15 \mathrm{mg} \mathrm{GAE} / \mathrm{g}$ DW and $75.07 \mathrm{mg} \mathrm{QE} / \mathrm{g}$ DW for the ultrasound extraction method. These data allowed us to check the importance of solvents amount in extraction, but that does not prevent us to say that more than $30 \mathrm{ml} / \mathrm{g}$ of the obtained phenolic content do not be more desirable as discussed by Zhu et al. [26] and Mohammadpour et al. [27]. However, we can conclude that the existence of an additional solvent in the system is equivalent to a low concentration of the solid, which causes a decrease in the phenomenon of cavitation. As indicated in the literature, the liquid-to-solid ratio has an effect considerable in obtaining phenolic compounds $[20,28]$.

3.1.4. Influence of Ethanol Concentration. The nature of the solvent is important for extracting molecules selectively, and it must have a strong affinity with a great capacity of dissolution. Water is used as a solvent for the extraction of biomolecules present in plant sources; its polarity dissolved several polar phenolic compounds. In addition, other solvents such as ethanol, methanol, acetone, ethyl acetate, and their mixtures with water were widely used for the extraction of phenolic compounds for the reason of absence of toxicity and abundance even if other more effective solvents than water and ethanol [29]. The different concentrations of ethanol have been varied from $0 \%$ to $100 \%$; these significant effects are shown in Figures 1(d) and 2(d). The highest phenolic content has been showed using $40 \%$ of hydroethanolic solvent, while extraction with mixture 100\% ethanol has a low value. Several similar results showed that the percentage of ethanol presents an important role in improving performance for phenolic extraction using ultrasound treatment [30-33].

\subsection{Response Surface Methodology}

3.2.1. Model Fitting and Response Surface Analysis. The response surface methodology (RSM) is performed for the 27 experimental tests. The regression equations were obtained by fitting the experimental data of each response in a polynomial model like the following equation (Table 3 ). The good adaptation of the regression model is estimated by the coefficient of determination $\left(R^{2}\right)$, which measured the adaptability in the response values, due to variation of the experiment's factors and their interactions. The model can fit well with the actual data when $R^{2}$ is close to one. The coefficients of determination of the model $\left(R^{2}\right)$ were 0.881 and 0.923 , which indicate that the obtained results would have good accuracy, which proved the capacity of the established model within the limits of the range of use.

The three-dimensional (3D) response surface presented 2 factors (axe $X$ and axe $Y$ ) and the response (axe $Z$ ) (Figures 3 and 4). Figures 3(a) and 4(a) show the interaction between the time and the temperature using ultrasound 

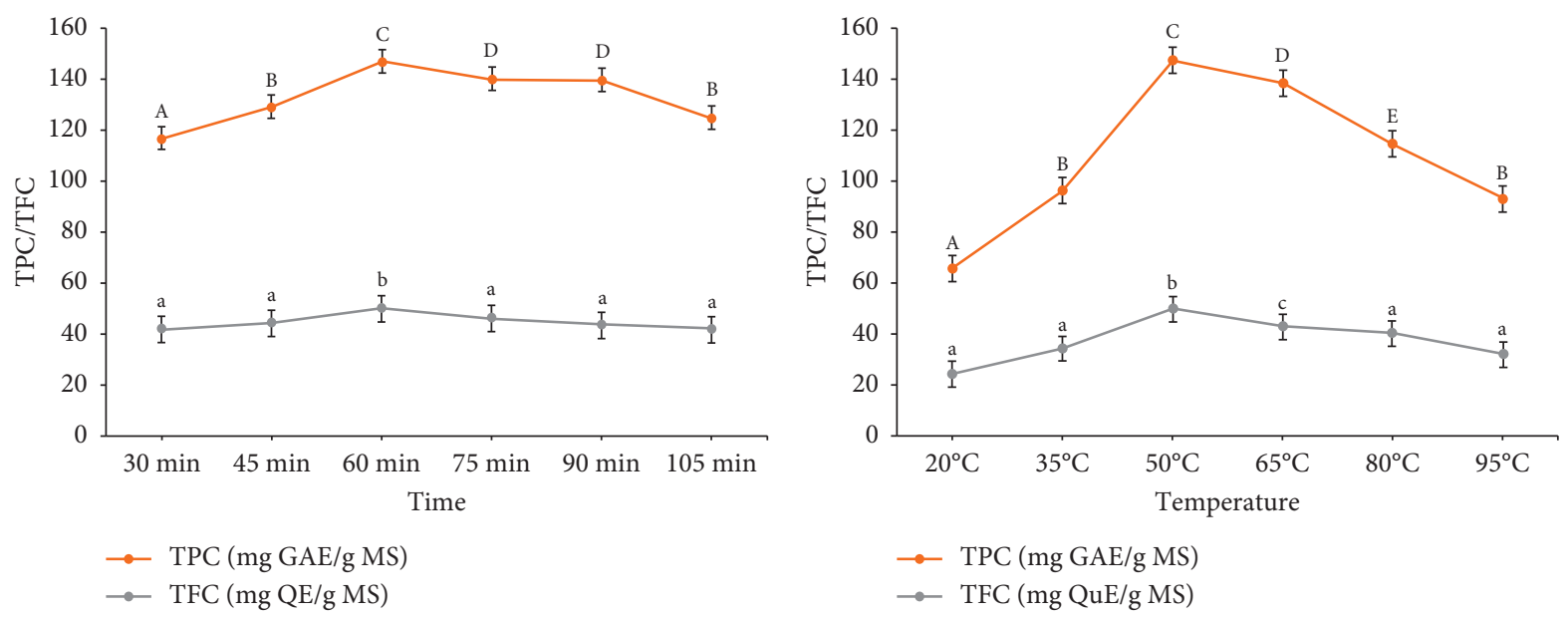

(a)

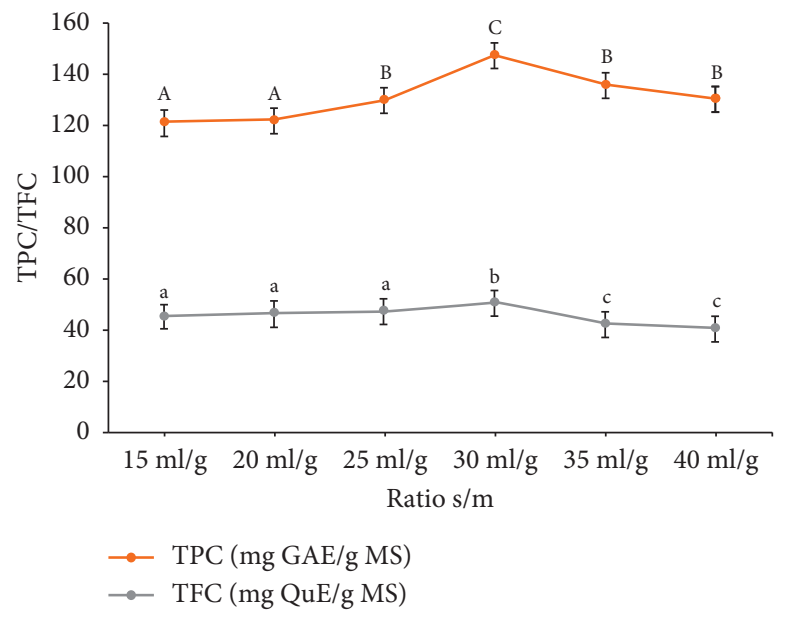

(c)

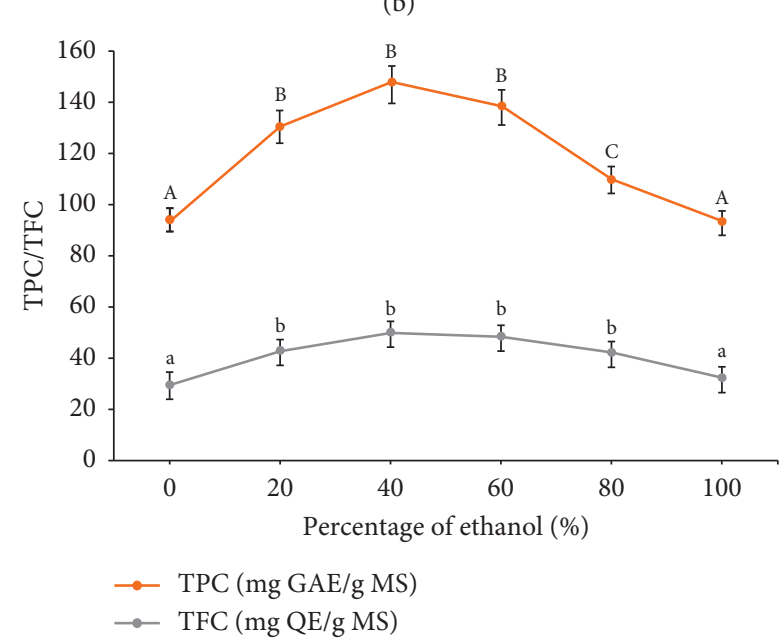

(d)

Figure 1: Effect of extraction time (a), temperature (b), ratio s/m (c), and ethanol (\%) (d) on total phenol and flavonoid contents from Eucalyptus marginata L. leaves using the maceration extraction method.

extraction and maceration methods, while $\mathrm{s} / \mathrm{m}$ ration and ethanol concentration have been fixed. Increasing $t$ and $T$ affects significantly TPC and TFC. However, after a long extraction time and high temperature, TPC and TFC decreased. These results could be explained by a degradation process of some phenolic compounds as mentioned previously by Zhang et al. (2019) and [34]. The effect of the $t$ and ratio is shown in Figures 3(b) and 4(b). The TPC and TFC increased with increasing these two factors where our research team concluded that increasing the ratio $\mathrm{s} / \mathrm{m}$ enhanced the solubility of the phenolics compounds. TPC and TFC reached its maximum after increasing $t$ and the percentage of ethanol (Figures 3(c) and 4(c)). As described by Do et al. [35], several polyphenols are soluble in organic solvent (ethanol). TPC and TFC increased with increasing the $T$ and the ratio $\mathrm{s} / \mathrm{m}$ (Figures $3(\mathrm{~d}$ ) and 4(d)). According to Kamarudin et al. [36], increasing $T$ enhanced the penetration of the solvents into the cells.

3.2.2. Optimization of the Extraction. Using the ultrasound method, the maximum of TPC ( 210 mg GAE/g DW) was obtained when the ultrasonic time was $49.9 \mathrm{~min}$, the temperature was $74.9^{\circ} \mathrm{C}$, the liquid-to-solid ratio was $39.5 \mathrm{ml} / \mathrm{g}$, and the percentage of ethanol was $58.48 \%$. However, the optimum conditions using maceration methods were as follows: $t=88 \mathrm{~min}, T=74.42^{\circ} \mathrm{C}$, liquid-tosolid $=40 \mathrm{ml} / \mathrm{g}$, and the percentage of ethanol equal to $59.65 \%$ to maximize the total phenolic compounds ( 150 mg GAE $g$ DW). For that reason, UAE could be considered as an economic and green extraction method for extraction of the bioactive compounds. The obtained results indicated that the UAE-RSM approach was very useful in order to improve the phenols and flavonoids contents in the plant material extracts.

3.3. Identification and Quantification of Phenolic Compounds in Eucalyptus marginata L. Extract. The chemical composition of the two Eucalyptus marginata L. extracts obtained after maceration and ultrasound-assisted extraction parameters was analyzed with LC-ESI-MS in the negative mode (Figure 5). Based on the mass spectra and comparison with reference compounds and with literature data $[4,6,7,37-39]$, the detected compounds were classified as 


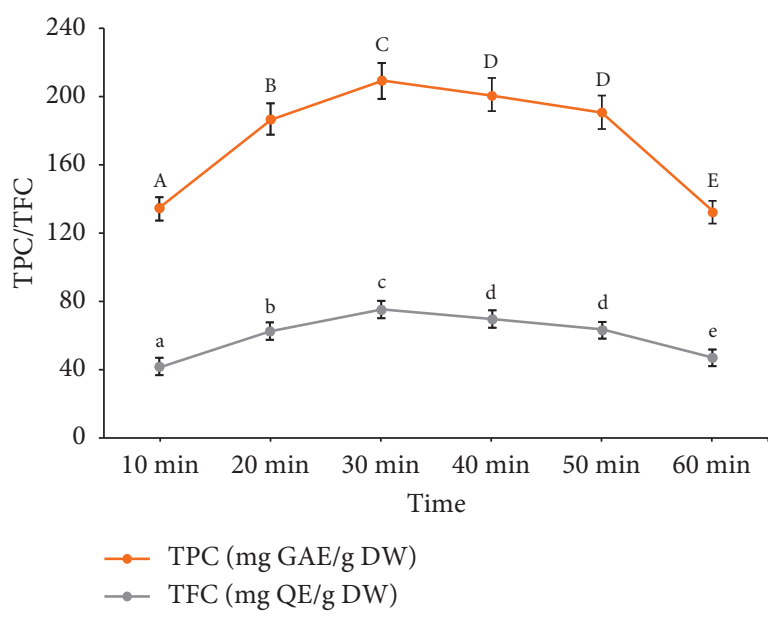

(a)

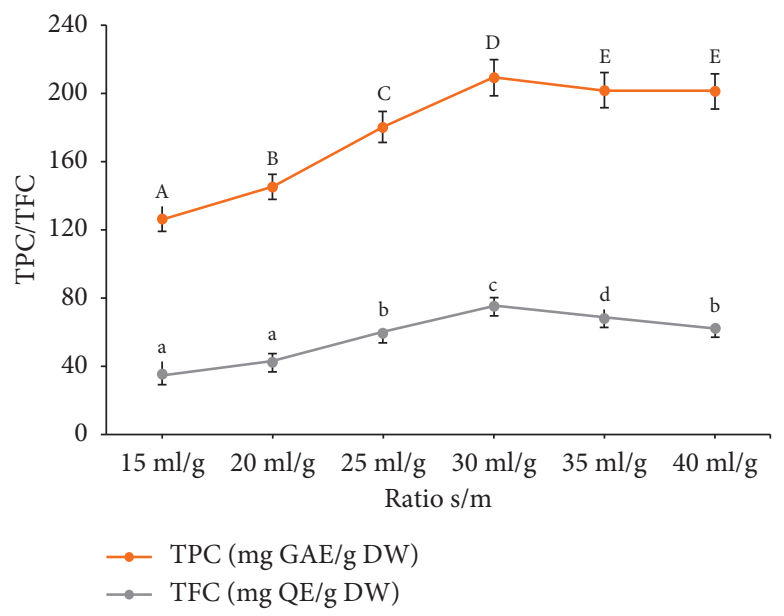

(c)

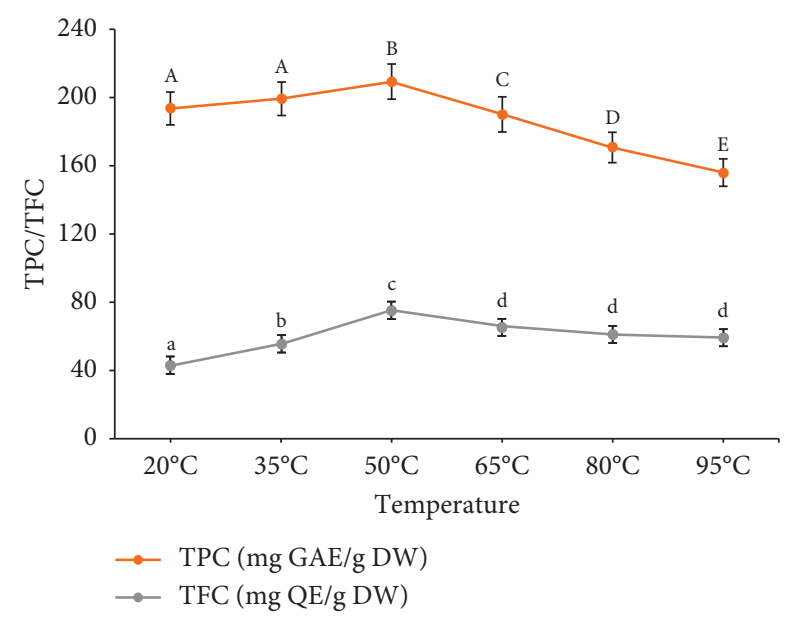

(b)

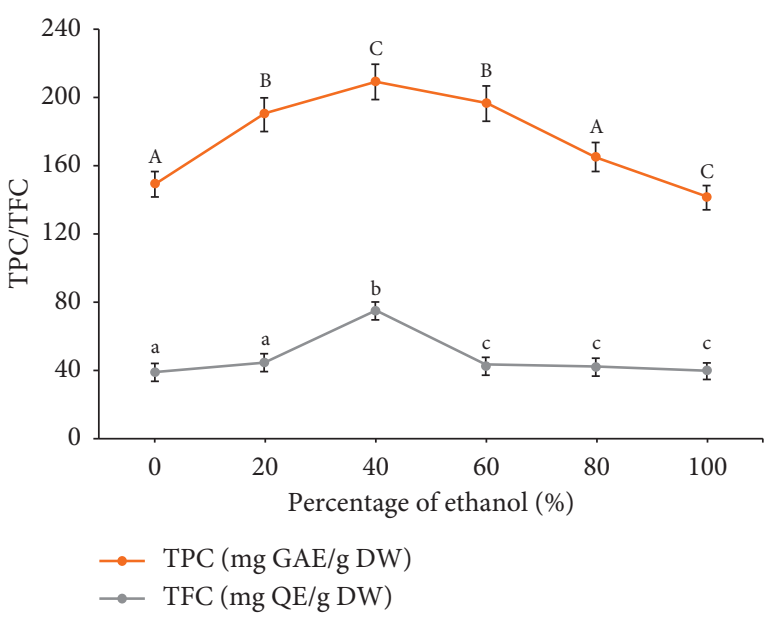

(d)

Figure 2: Effect of extraction time (a), temperature (b), ratio s/m (c), and ethanol (\%) (d) on total phenol and flavonoid contents from Eucalyptus marginata L. leaves using the ultrasound-assisted extraction method.

TABLE 3: The responses in TPC and TFC for the two extraction methods.

$$
\begin{aligned}
& Y(\mathrm{TPC})_{M E}=150.789+7.180 X_{1}+1.056 X_{2}+2.948 X_{3}+2.769 X_{4}-11.638 X_{2}^{1}-19.335 X_{2}^{2}-12.9 X_{3}^{2} \\
& -20.815 X_{4}^{2}-0.335 X_{1} X_{2}-0.083 X_{1} X_{3}-2.124 X_{2} X_{3}+0.581 X_{1} X_{4}-0.991 X_{2} X_{4}+0.061 X_{3} X_{4} . \\
& Y(\mathrm{TFC})_{M E}=50.457+0.690 X_{1}-0.506 X_{2}-1.349 X_{3}+3.938 X_{4}-1.502 X_{1}^{2}-4.098 X_{2}^{2}-4.176 X_{3}^{2} \\
& -7.014 X_{4}^{2}-0.190 X_{1} X_{2}+0.335 X_{1} X_{3}-0.001 X_{2} X_{3}+0.371 X_{1} X_{4}-0.335 X_{2} X_{4}-0.350 X_{3} X_{4} . \\
& Y(\mathrm{TPC})_{\mathrm{UAE}}=209.729+12.39 X_{1}-6.036 X_{2}+20.175 X_{3}+10.762 X_{4}-13.156 X_{1}^{2}-11.804 X_{2}^{2}-18.185 X_{3}^{2} \\
& -8.463 X_{4}^{2}+0.663 X_{1} X_{2}-0.368 X_{1} X_{3}+0.372 X_{2} X_{3}+0.354 X_{1} X_{4}+0.402 X_{2} X_{4}-0.917 X_{3} X_{4} . \\
& Y(\mathrm{TFC})_{\mathrm{UAE}}=70.521+0.973 X_{1}-2.142 X_{2}+6.232 X_{3}+2.786 X_{4}-10.584 X_{1}^{2}-4.328 X_{2}^{2} \\
& -2.392 X_{3}^{2}+0.244 X_{4}^{2}-0.172 X_{1} X_{2}+1.237 X_{2} X_{3}+0.469 X_{1} X_{4}-2.591 X_{2} X_{4}-0.196 X_{3} X_{4} .
\end{aligned}
$$

TPC, total phenol content expressed in mg GAE/g DW; TFC, total flavonoid content expressed in mg QE/g DW; ME, maceration extraction; UAM, ultrasound-assisted extraction; $X_{1}$, extraction time; $X_{2}$, temperature; $X_{3}$ solvent-solid ratio; $X_{4}$, ethanol concentration.

phenolic acids such as quinic, gallic, protocatechuic, $p$ coumaric, salviolinic, trans-ferulic, and trans-cinnamic acids and flavonoids such as hyperoside, rutin, quercetrin, naringin, quercetin, and naringenin. Retention times, pseudomolecular ions, and the concentration of each identified phenolic compound are given in Table 4. For example, compound 7 ( $t_{\mathrm{R}} 21.742 \mathrm{~min}$ ) was identified as quercetin aglycon that was assigned according to the presence of a main peak at $\mathrm{m} / z 609$ as well as a strong peak at $\mathrm{m} / z 301$ in its ESI-mass spectrum at the negative mode. The compound 7 $\mathrm{MS}^{2}$ mass spectrum's showed fragments at $\mathrm{m} / z 463$ and 301, which could be attribute to loss of rhamnosyl and glucosyl moieties, respectively. These results confirmed the presence of a rutin [7]. Additionally, the mass spectrum of compound 12 showed a peak at $\mathrm{m} / z 301$ whose spectrum of $\mathrm{MS}^{2}$ fragmentation indicated various ionic species: 273, 257, 193, 

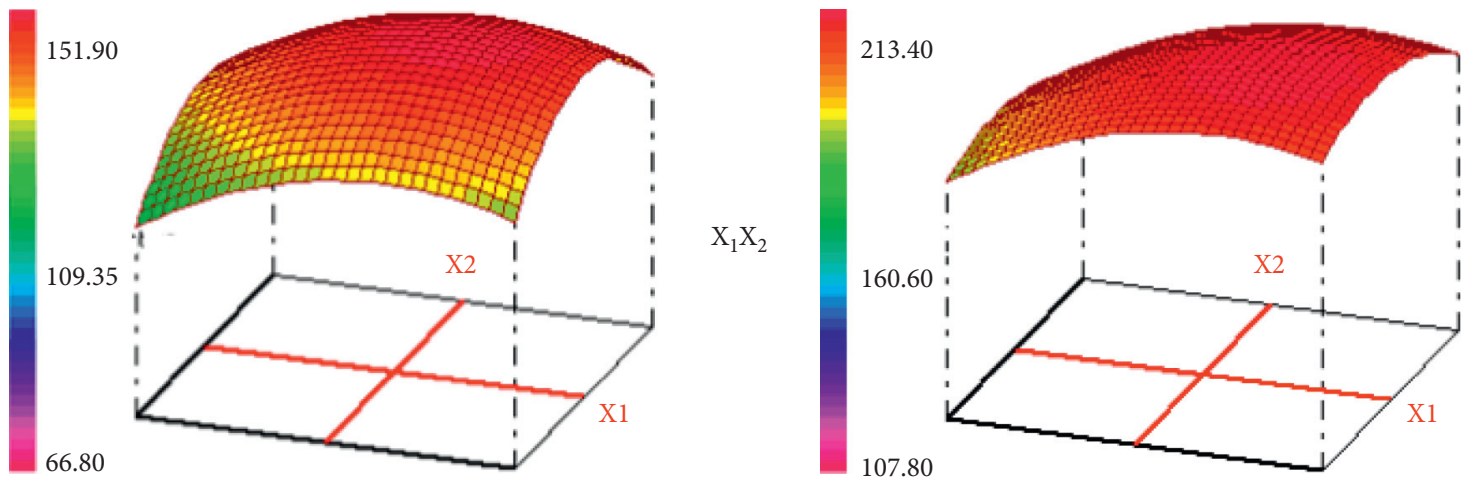

(a)
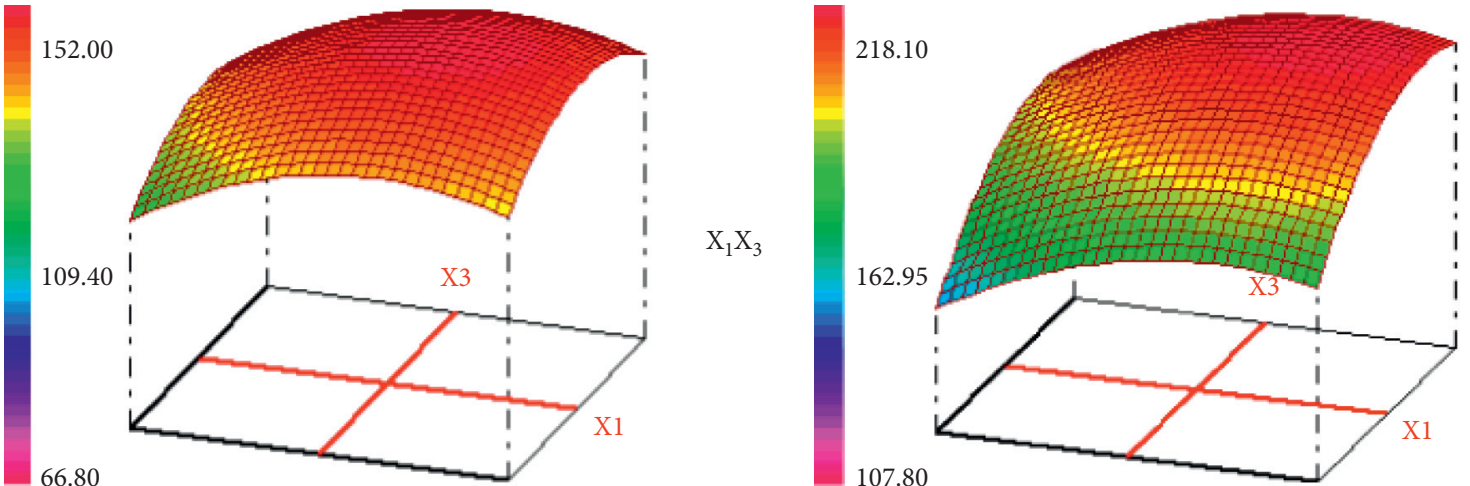

(b)
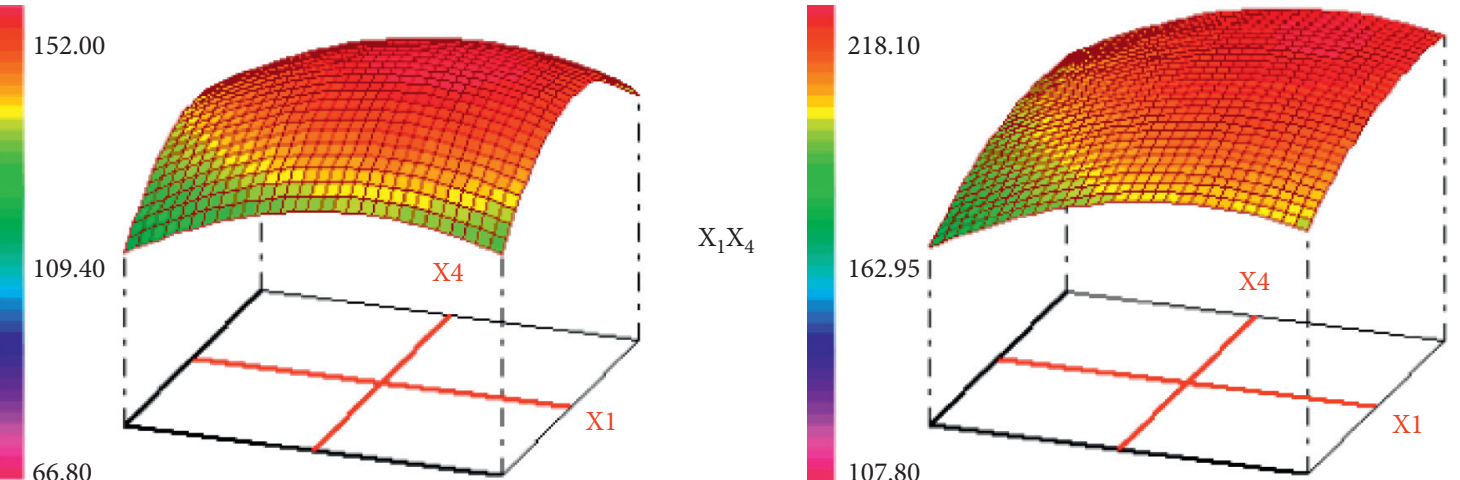

(c)

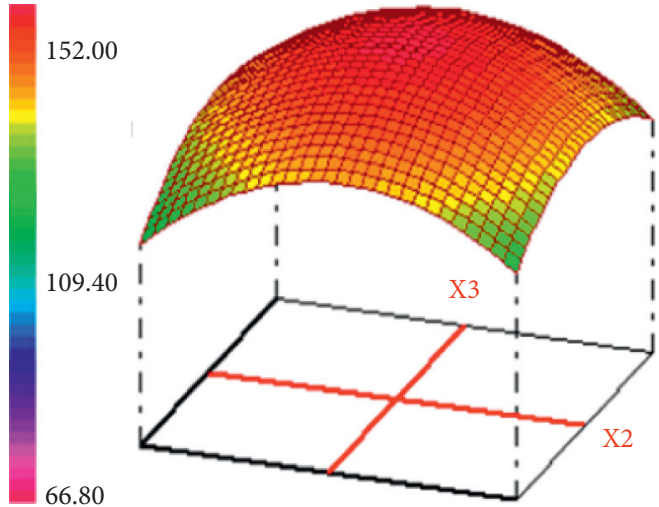

218.40

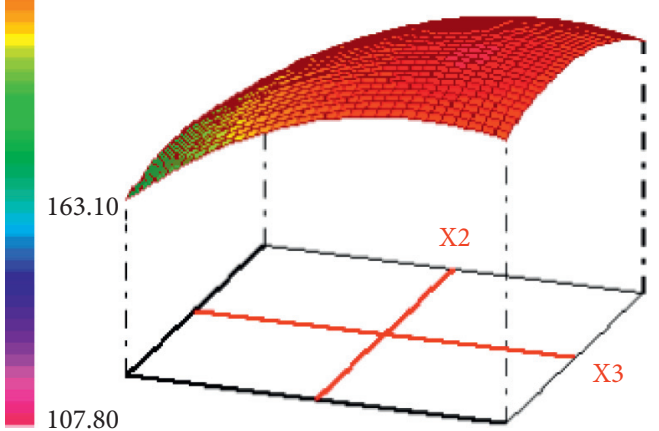

(d)

Figure 3: Continued. 

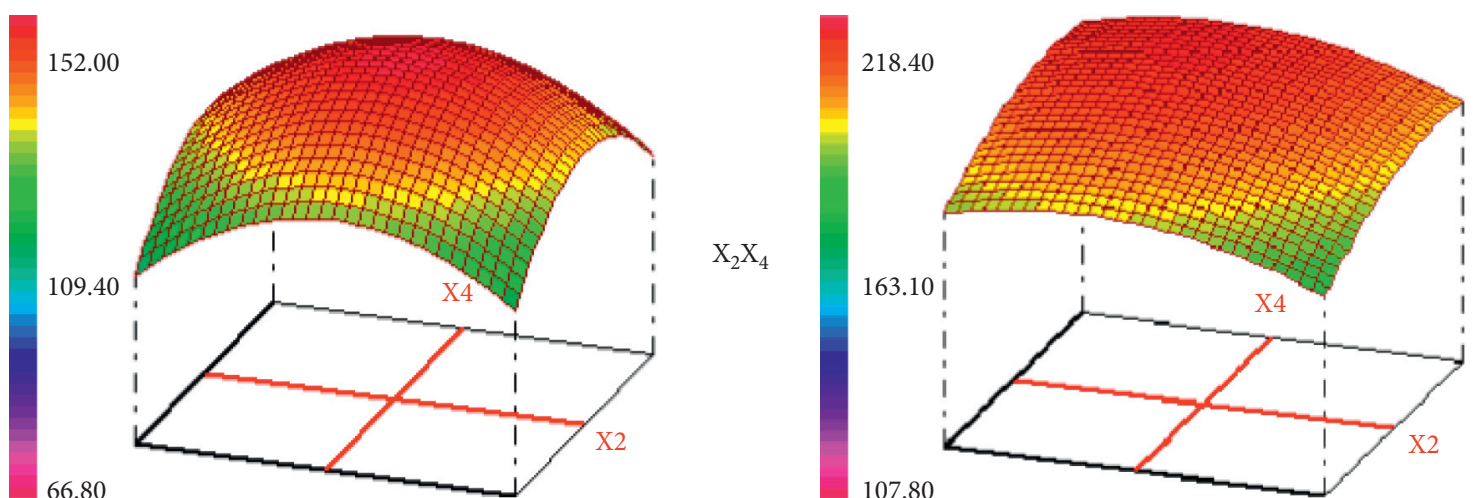

(e)
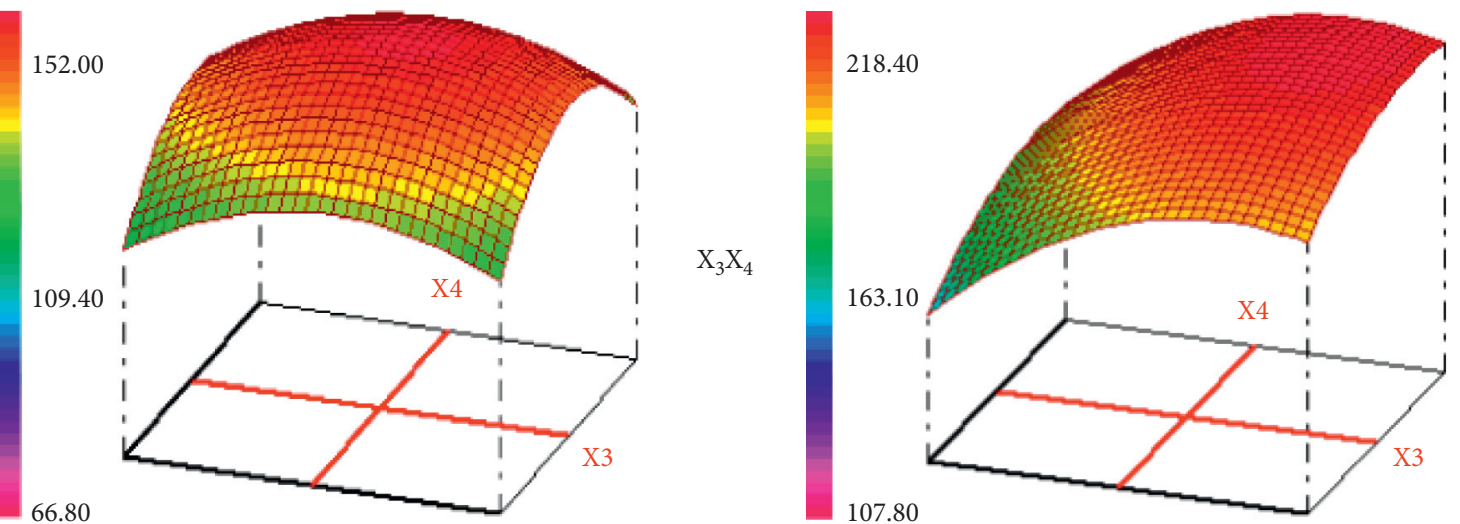

(f)

FIGURE 3: Response surface plot of TPC (mg GAE g-1 DW) of Eucalyptus marginata leaves extracts as a function of time, temperature, ratio $\mathrm{s} / \mathrm{m}$, and ethanol concentration obtained by maceration and ultrasound-assisted extraction methods. The extraction time (min, $X_{1}$ ), temperature $\left({ }^{\circ} \mathrm{C}, X_{2}\right)$, liquid/solid ratio $\left(\mathrm{ml} / \mathrm{g}, X_{3}\right)$, and ethanol concentration $\left(\%, X_{4}\right)$.
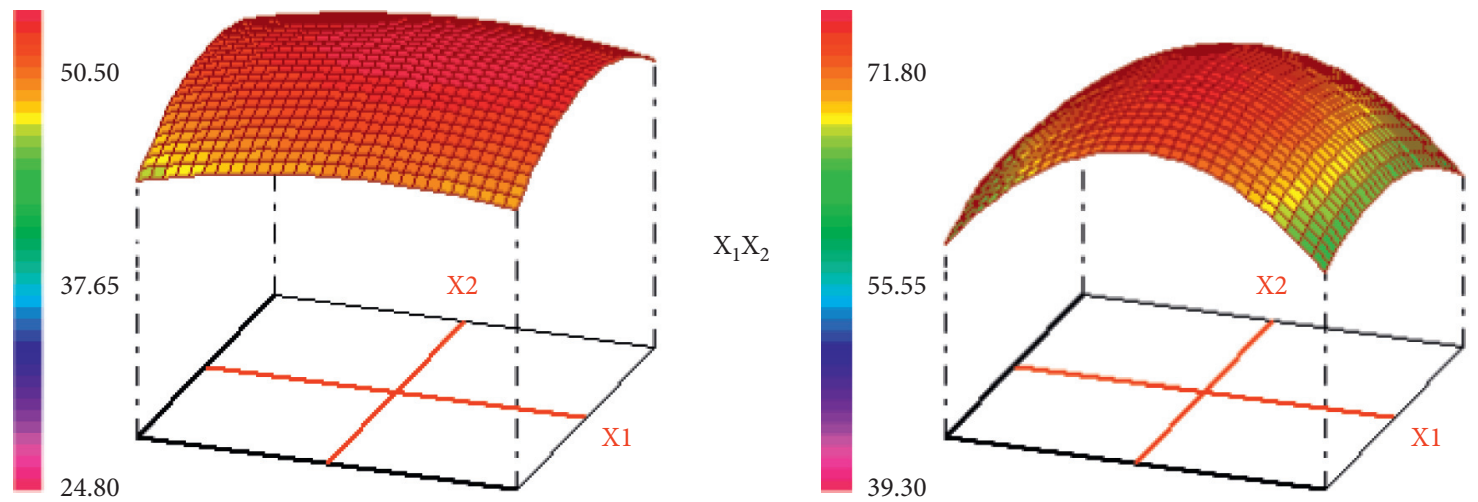

(a)

FIGURE 4: Continued. 

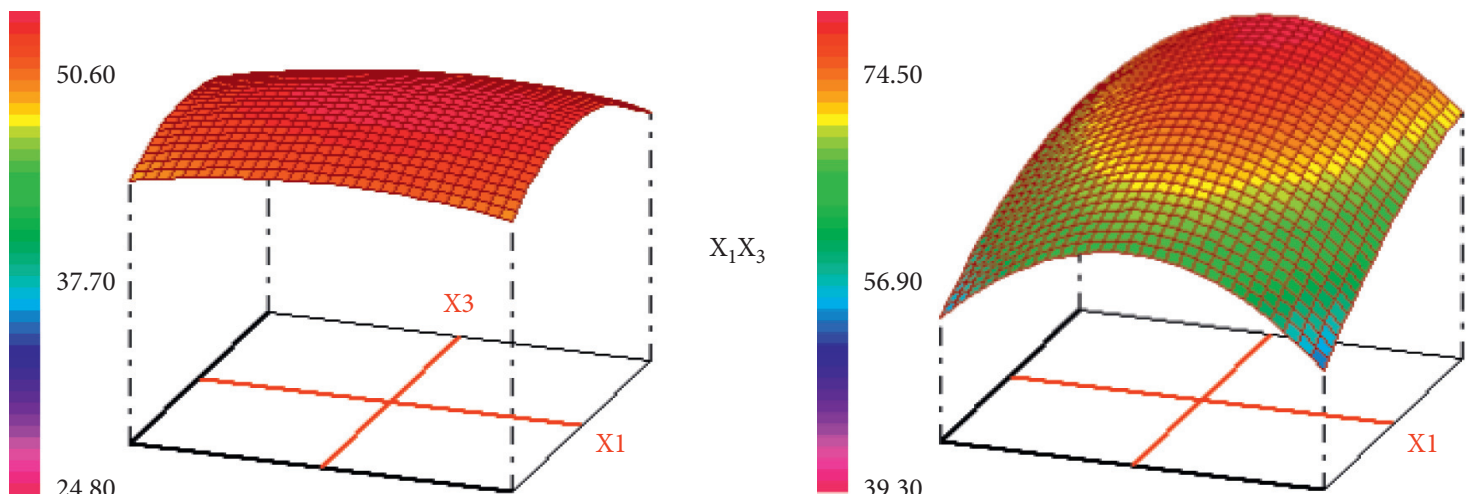

(b)
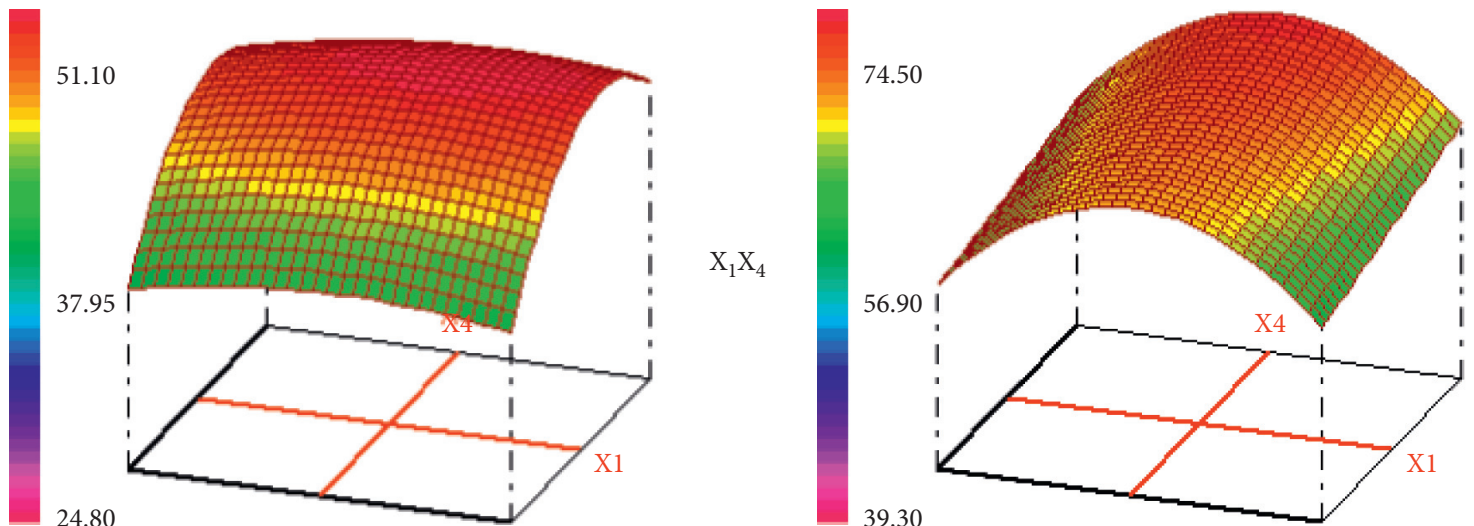

(c)
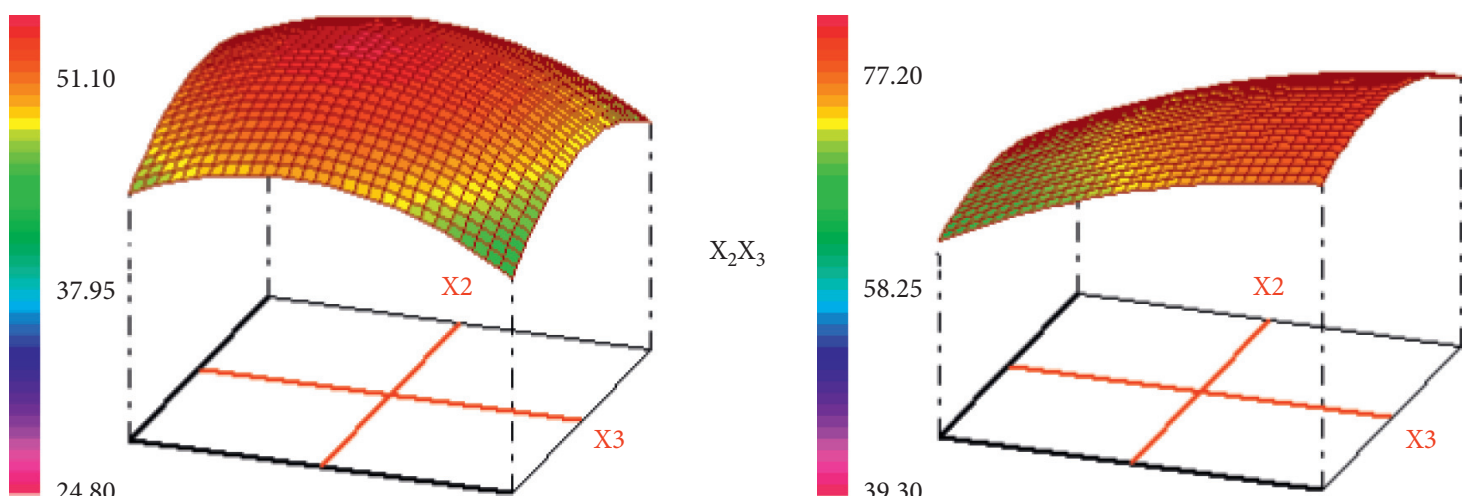

(d)
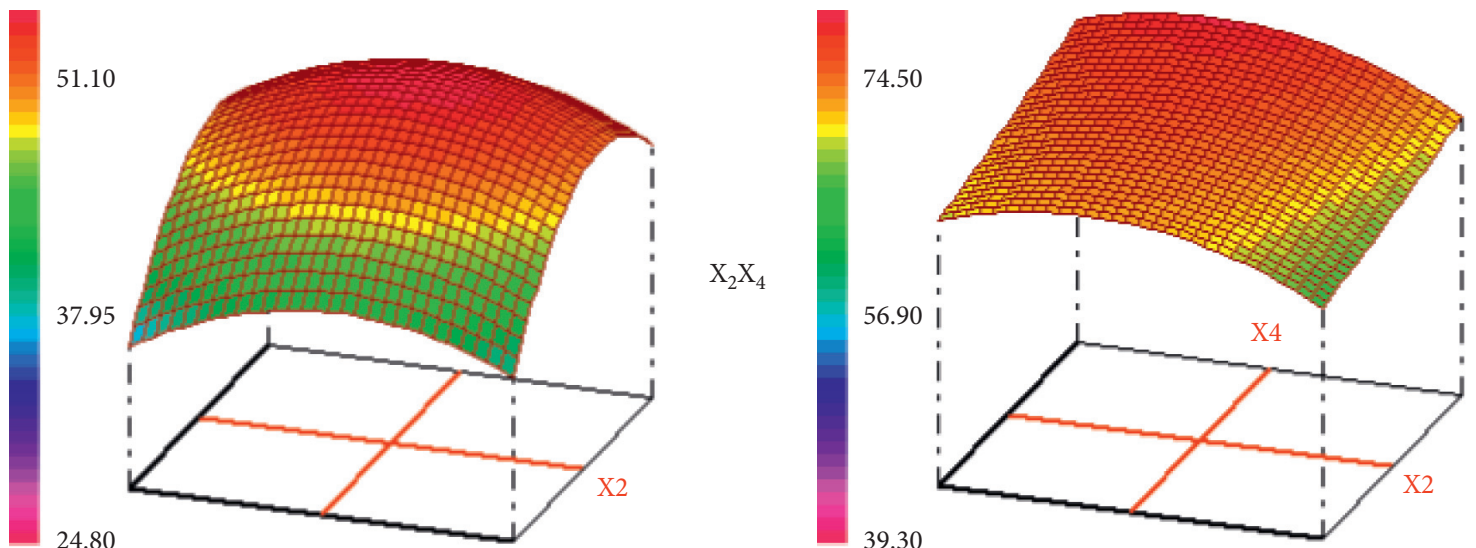

(e)

Figure 4: Continued. 

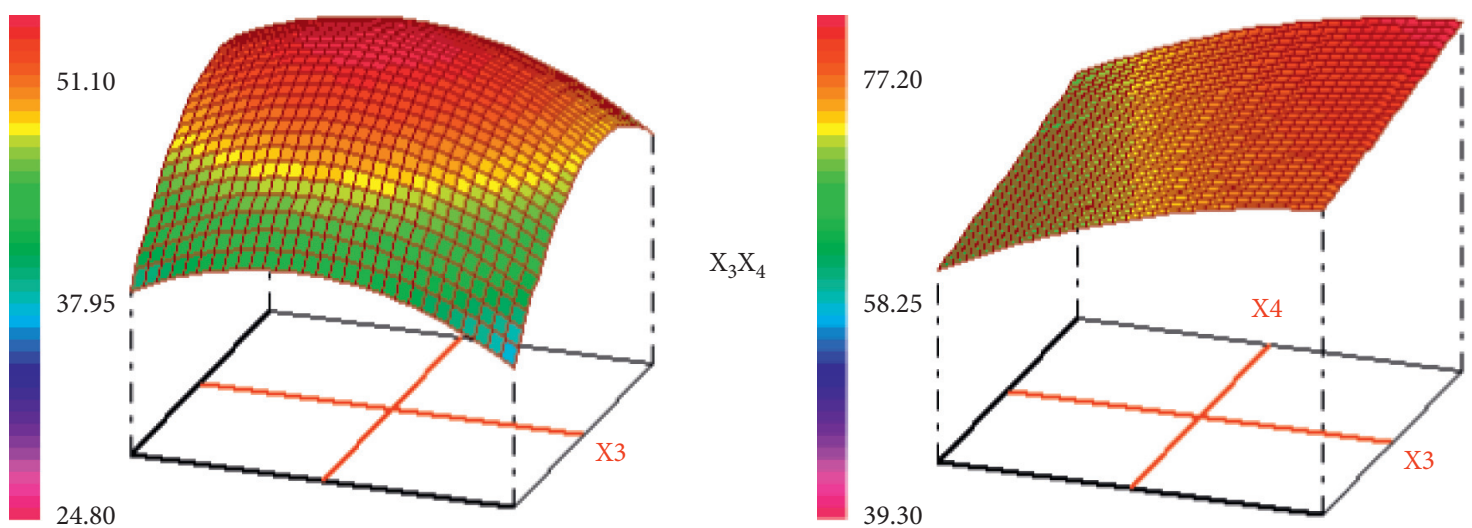

(f)

FIGURE 4: Response surface plot of TFC (mg QE g-1 DW) of Eucalyptus marginata leaves extracts as a function of time, temperature, ratio s/ $\mathrm{m}$, and ethanol concentration obtained by maceration and ultrasound-assisted extraction methods. The extraction time (min, $X_{1}$ ), temperature $\left({ }^{\circ} \mathrm{C}, X_{2}\right)$, liquid/solid ratio $\left(\mathrm{ml} / \mathrm{g}, X_{3}\right)$, and ethanol concentration $\left(\%, X_{4}\right)$.

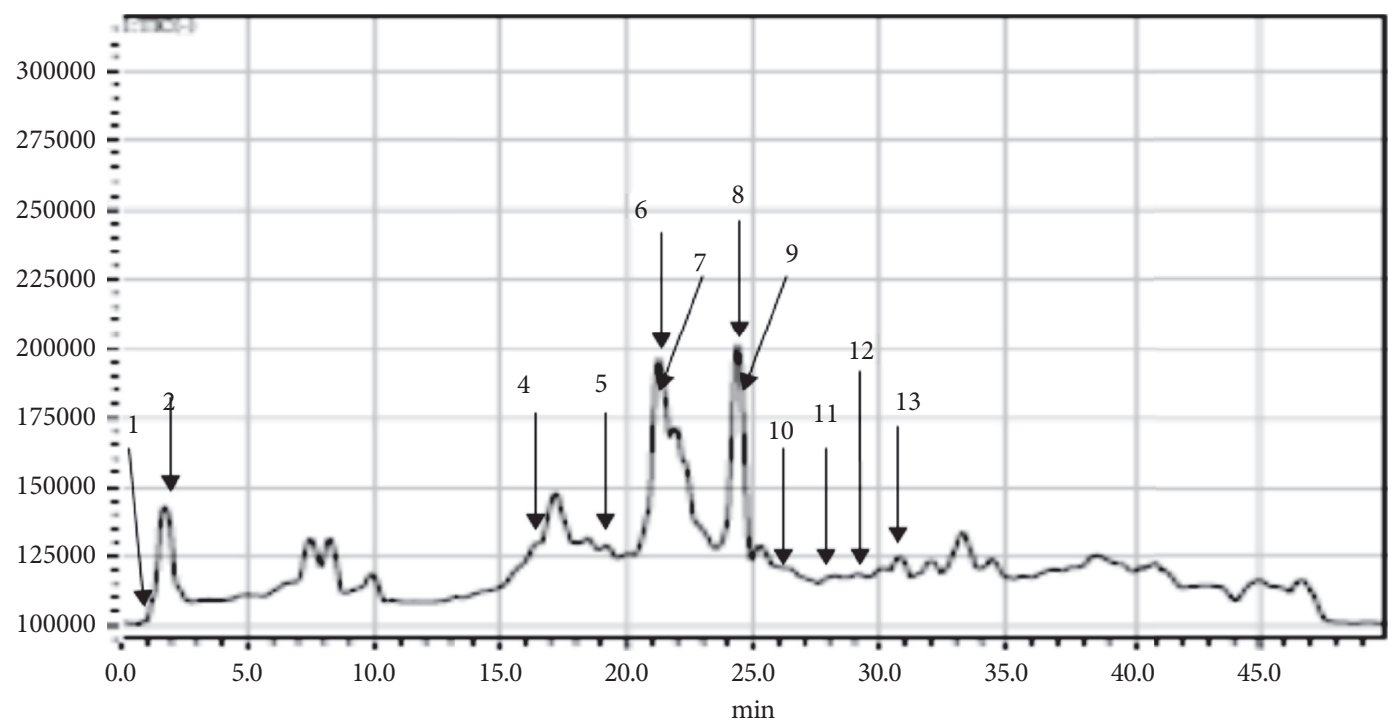

(a)

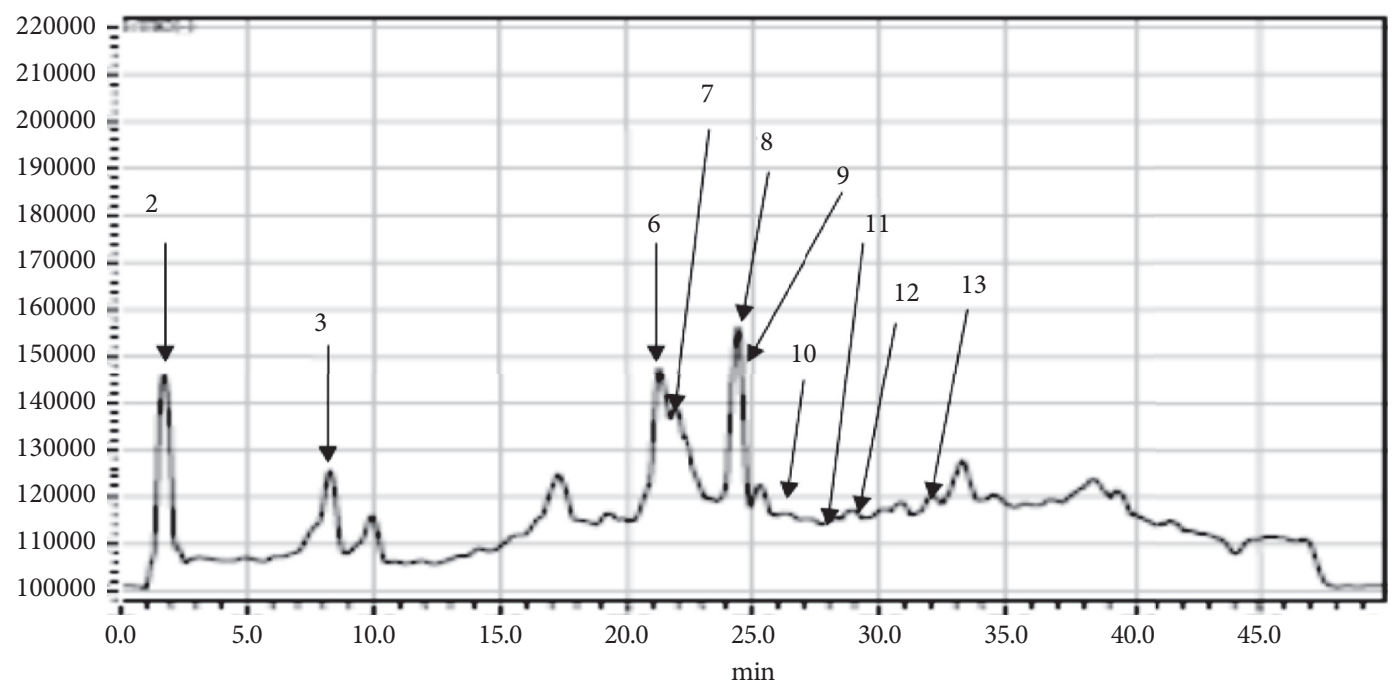

(b)

FiguRE 5: HPLC chromatograms of the phenolic compounds of the extracts obtained by maceration (a) and ultrasound (b) extraction methods. 1, quinic acid; 2, gallic acid; 3, protocatechuic acid; 4, $p$-coumaric acid; 5, trans-ferulic acid; 6, hyperoside; 7, rutin; 8, quercetrin; 9 , naringin; 10, salviolinic acid; 11, trans-cinnamic acid; 12, quercetin; 13, naringenin. 
TABle 4: Phenolic compounds detected in Eucalyptus marginata L. leaves optimum extraction condition extracts.

\begin{tabular}{|c|c|c|c|c|c|c|c|}
\hline$N$ & Compounds & Formula & $\begin{array}{l}\text { Molecular } \\
\text { mass }\end{array}$ & $\begin{array}{c}{[\mathrm{M}-\mathrm{H}]^{-}} \\
\mathrm{m} / z\end{array}$ & $\begin{array}{l}\text { Retention time } \\
\quad(\min )\end{array}$ & $\begin{array}{l}\text { Maceration } \\
(\mu \mathrm{g} / \mathrm{g} \mathrm{DW})^{*}\end{array}$ & $\begin{array}{l}\text { Ultrasound } \\
(\mu \mathrm{g} / \mathrm{g} \mathrm{DW})^{*}\end{array}$ \\
\hline 1 & Quinic acid & $\mathrm{C}_{7} \mathrm{H}_{12} \mathrm{O}_{6}$ & 192 & 191 & 1.750 & $1.65 \pm 0.02^{\mathrm{a}}$ & ND \\
\hline 2 & Gallic acid & $\mathrm{C}_{7} \mathrm{H}_{6} \mathrm{O}_{5}$ & 170 & 169 & 2.627 & $12.17 \pm 0.06^{\mathrm{a}}$ & $27.77 \pm 0.06^{\mathrm{b}}$ \\
\hline 3 & Protocatechuic acid & $\mathrm{C}_{7} \mathrm{H}_{6} \mathrm{O}_{4}$ & 154 & 153 & 8.617 & ND & $37.66 \pm 0.04^{\mathrm{b}}$ \\
\hline 4 & $p$-Coumaric acid & $\mathrm{C}_{9} \mathrm{H}_{8} \mathrm{O}_{3}$ & 164 & 163 & 16.217 & $4.67 \pm 0.06^{\mathrm{a}}$ & ND \\
\hline 5 & trans-Ferulic acid & $\mathrm{C}_{10} \mathrm{H}_{10} \mathrm{O}_{4}$ & 194 & 193 & 19.150 & $0.12 \pm 0.03^{\mathrm{a}}$ & ND \\
\hline 6 & $\begin{array}{l}\text { Hyperoside (quercetin-3-O- } \\
\text { galactoside) }\end{array}$ & $\mathrm{C}_{21} \mathrm{H}_{20} \mathrm{O}_{12}$ & 464 & 463 & 20.744 & $96.47 \pm 0.08^{\mathrm{a}}$ & $39.19 \pm 0.03^{b}$ \\
\hline 7 & Rutin (quercetin-3-O-rutinoside) & $\mathrm{C}_{27} \mathrm{H}_{30} \mathrm{O}_{16}$ & 610 & 609 & 21.742 & $0.23 \pm 0.06^{\mathrm{a}}$ & $0.08 \pm 0.09^{\mathrm{b}}$ \\
\hline 8 & $\begin{array}{l}\text { Quercetrin (quercetin-3-O- } \\
\text { rhamnoside) }\end{array}$ & $\mathrm{C}_{21} \mathrm{H}_{20} \mathrm{O}_{11}$ & 448 & 447 & 24.147 & $181.10 \pm 0.05^{\mathrm{a}}$ & $150.78 \pm 0.02^{\mathrm{b}}$ \\
\hline 9 & $\begin{array}{l}\text { Naringin (naringenin-7-O- } \\
\text { neohesperidoside) }\end{array}$ & $\mathrm{C}_{27} \mathrm{H}_{32} \mathrm{O}_{14}$ & 580 & 579 & 24.246 & $19.00 \pm 0.05^{\mathrm{a}}$ & $8.80 \pm 0.07^{\mathrm{b}}$ \\
\hline 10 & Salviolinic acid & $\mathrm{C}_{7} \mathrm{H}_{6} \mathrm{O}_{3}$ & 138 & 137 & 26.643 & $0.74 \pm 0.04^{\mathrm{a}}$ & $0.75 \pm 0.05^{\mathrm{a}}$ \\
\hline 11 & trans-Cinnamic acid & $\mathrm{C}_{9} \mathrm{H}_{8} \mathrm{O}_{2}$ & 148 & 147 & 28.794 & $7.11 \pm 0.07^{\mathrm{a}}$ & $21.99 \pm 0.01^{\mathrm{b}}$ \\
\hline 12 & Quercetin & $\mathrm{C}_{15} \mathrm{H}_{10} \mathrm{O}_{7}$ & 302 & 301 & 29.118 & $3.21 \pm 0.01^{\mathrm{a}}$ & $2.06 \pm 0.02^{\mathrm{b}}$ \\
\hline 13 & Naringenin & $\mathrm{C}_{15} \mathrm{H}_{12} \mathrm{O}_{5}$ & 272 & 271 & 31.478 & $1.23 \pm 0.09^{\mathrm{a}}$ & $1.03 \pm 0.06^{\mathrm{b}}$ \\
\hline
\end{tabular}

${ }^{*}$ Concentration expressed as $\mu \mathrm{g} / \mathrm{g}$ of DW. ND, not detected; DW, dry weight. Results are expressed as mean \pm standard deviation of three determinations. Means with different letters in the same line were significantly different at $p<0.05$.

and 121. The main one fragment caused a loss of $28 \mathrm{Da}$, giving rise to a fragment ion at $\mathrm{m} / z 273$. The fragment ion at $\mathrm{m} / z 257$ was also obtained by the loss a $\mathrm{CO}_{2}$ molecule. While, the ions at $\mathrm{m} / z 193$ and 121 were obtained, respectively, by the elimination of $-\mathrm{C}_{6} \mathrm{H}_{4} \mathrm{O}_{2}$ and $\mathrm{C}_{7} \mathrm{H}_{4} \mathrm{O}_{2}$ from the ion to $\mathrm{m} / z$ 301. These results are consistent with the presence of quercetin, as described above, previously by Rigane et al. [37]. On the other hand, compound 13 was identified as naringenin, according to the $[\mathrm{M}-\mathrm{H}]^{-}$ion at $\mathrm{m} / z 271$ as well as the ions produced in the $\mathrm{MS}^{2}$ spectrum at $\mathrm{m} / z 227,177$, 151,119 , and 107, which are in agreement with the fragments obtained for its standard [40].

The quantification of the identified phenolic compounds given in Table 4 showed a significant difference between the two extraction methods $(p<0.05)$. Therefore, our research team showed that the main phenolic acid found in the Eucalyptus marginata L. obtained by ultrasound-assisted extraction was protocatechuic acid which was present with $37.664 \mu \mathrm{g} / \mathrm{g}$ DW followed by gallic acid $(27.77 \mu \mathrm{g} / \mathrm{g}$ DW). On the other hand, gallic acid was the major phenolic acid present in the Eucalyptus marginata leaves obtained by maceration $(12.17 \mu \mathrm{g} / \mathrm{g}$ DW). On the other hand, salviolinic acid was present in the two studied samples $(\sim 0.75 \mu \mathrm{g} / \mathrm{g}$ DW). In addition, from Table 4 , we can conclude that quercetrin was the main flavonoid compound quantified in the two studied extracts (181.10 and $150.78 \mu \mathrm{g} / \mathrm{g}$ DW obtained, respectively, by maceration and ultrasound-assisted extraction), followed by hyperoside (96.47 and $39.19 \mu \mathrm{g} / \mathrm{g}$ DW obtained, respectively, by maceration and ultrasoundassisted extraction), naringin (19.00 and $8.80 \mu \mathrm{g} / \mathrm{g}$ DW obtained, respectively, by maceration and ultrasoundassisted extraction), and quercetin (3.21 and $2.06 \mu \mathrm{g} / \mathrm{g} \mathrm{DW}$ obtained, respectively, by maceration and ultrasoundassisted extraction). On the other hand, naringenin and rutin were present in very low amounts: $\sim 1.2 \mu \mathrm{g} / \mathrm{g}$ DW and $<$ $0.2 \mu \mathrm{g} / \mathrm{g}$ DW obtained, respectively, by maceration and ultrasound-assisted extraction. According to Al-Sayed et al.
[41], the main nonvolatile compounds identified in Eucalyptus were phenolic compounds that contribute significantly to the antioxidant activities of extracts. In general, several phenolic compounds such as gallic, protocatechuic, and ellagic acids as well as quercetin, quercetin glycoside, naringenin, catechin, epicatechin, rutin, quercitrin, apigenin, and myricetin have been isolated from Eucalyptus extracts [41, 42]. Moreover, Santos et al. [40] identified epicatechin, catechin, quercetin glucuronide, ellagic acid rhamnoside, ellagic acid, galloyl-bis-hexa-hydroxyphenyl (HHDP)-glucose, gallic acid, chlorogenic acid, and methyl ellagic acid pentose in Eucalyptus grandis, Eucalyptus urograndis, and Eucalyptus maidenii extracts. In addition, Santos and coworkers [40] identified and quantified the phenolic compounds present in Eucalyptus grandis, Eucalyptus urograndis, and Eucalyptus maidenii using the HPLCMS technique. By comparing this study with those obtained by our research team, we can conclude that the phenolic composition present in the Eucalyptus species woods and leaves varied significantly. From these results, we concluded that this study could provide useful information for industry to produce the potentially bioactive compound extracted from Eucalyptus marginata L. leaves using optimum condition parameters.

\section{Conclusion}

To the best of our knowledge, this study successfully used RSM in order to optimize the extraction of total phenolic and total flavonoid from Eucalyptus marginata L. leaves using maceration and ultrasound-assisted extraction methods with regards to extraction time, temperature, liquid/solid ratio, and ethanol concentration. Therefore, the optimum maceration condition's should be as follows: $t=88 \mathrm{~min}, T=74.42^{\circ} \mathrm{C}$, liquid-to-solid ratio $=40 \mathrm{ml} / \mathrm{g}$, and the percentage of ethanol was equal to $59.65 \%$, while the best conditions for ultrasound were obtained as follows: 
$t=49.9 \mathrm{~min}, T=74.9^{\circ} \mathrm{C}$, ratio solvent-solid $=39.5 \mathrm{ml} / \mathrm{g}$, and percentage of ethanol was $58.48 \%$. The levels of phenolic compounds found by RSM were, respectively, $\sim 150 \mathrm{mg} \mathrm{GAE} / \mathrm{g}$ DW and $210 \mathrm{mg}$ GAE/g DW for maceration and ultrasound-assisted methods.

Thus, the proposed method meets the terms of green process definition, since it reduces process time, allows use of alternative solvents (aqueous ethanol) and renewable natural products, and ensures a safe and high-quality extract/product.

\section{Data Availability}

The data that support the findings of this study are available from the corresponding author upon request.

\section{Additional Points}

Practical applications: Eucalyptus marginata L. leaves are treated using the "green" technique by elaboration of an efficient alternative protocol in order to obtain a phenolic rich extract. Therefore, a response surface methodology was used as a new tool for optimization of ultrasound and maceration methods process parameters including extraction time $(\mathrm{min})$, temperature $\left({ }^{\circ} \mathrm{C}\right)$, liquid-to-solid ratio $(\mathrm{ml} / \mathrm{g})$, and ethanol concentration (\%). The wide range of phenolic compounds discovered in Eucalyptus marginata provides abundant natural health-promoting agents for further applications in medicine and functional food.

\section{Conflicts of Interest}

The authors report that they have no conflicts of interest.

\section{Authors' Contributions}

Ghayth Rigane and Hanene Ghazghazi contributed equally to this work. Soumaya Hasni and Hajer Riguene performed practical experiences and wrote, followed, and checked the obtained results. Moufida A. Oueslati, Olfa Khedher and Amir Bouallegue performed some practical experiences, coordinated all the analyses, and calculated the results and statistics. Hanene Ghazghazi, Ghayth Rigane, and Ridha Ben Salem supervised the scientific study.

\section{Acknowledgments}

The authors thank the Ministry of Higher Education and Scientific Research, Tunisia, as well as Ministry of Agriculture, for their financial support and Professor Mohamed Rigane for useful discussion about English.

\section{References}

[1] B. Gullón, P. Gullón, T. A. Lú-Chau, M. T. Moreira, J. M. Lema, and G. Eibes, "Optimization of solvent extraction of antioxidants from Eucalyptus globulus leaves by response surface methodology: characterization and assessment of their bioactive properties," Industrial Crops and Products, vol. 108, pp. 649-659, 2017.
[2] G. Rigane, J. Jebali, J. Jebali et al., "Chemical composition and biological activities of pinus halepensis Mill. oil," Revue Roumaine de Chimie, vol. 64, no. 11, pp. 999-1006, 2019.

[3] H. Ghazghazi, B. Essghaier, H. Riguene et al., "Phytochemical analysis, antioxidant and antimicrobial activities of eucalyptus essential oil: a comparative study between eucalyptus marginata L. and eucalyptus paucilora L," Revue Roumaine de Chimie, vol. 64, no. 12, pp. 1055-1062, 2019.

[4] H. Ben Salah, S. Smaoui, R. Abdennabi, and N. Allouche, "LCESI-MS/MS phenolic profile of volutaria lippii (L.) cass. Extracts and evaluation of their in vitro antioxidant, antiacetylcholinesterase, antidiabetic, and antibacterial activities," Evidence-based Complementary and Alternative Medicine, vol. 2019, 2019.

[5] O. Khedher, G. Rigane, R. B. Salem, and Y. Moussaoui, "Optimization of polyphenols recovery from schinus molle L. Peel using response surface methodology (RSM)," Chemistry Africa, vol. 3, no. 3, pp. 813-820, 2020.

[6] M. Ben Hmed, G. Rigane, G. Rigane, R. Ben Salem, N. Zouari, and S. Cherif, "Phytochemical and antioxidant activities of Schinus molle L. extract," Revue Roumaine de Chimie, vol. 65, no. 2, pp. 173-178, 2020.

[7] A. Mahdhi, H. Ghazghazi, M. El Aloui, R. Ben Salem, and G. Rigane, "Identification and quantification of phenolic and fatty acid profiles in Pinus halepensis mill. seeds by LC-ESIMS and GC: effect of drying methods on chemical composition," Food Sciences and Nutrition, vol. 9, no. 4, pp. 1907-1916, 2021.

[8] M. Saifullah, R. McCullum, A. McCluskey, and Q. Vuong, "Comparison of conventional extraction technique with ultrasound assisted extraction on recovery of phenolic compounds from lemon scented tea tree (Leptospermum petersonii) leaves," Heliyon, vol. 6, no. 4, Article ID e03666, 2020.

[9] Y. Ezzoubi, M. Fadil, D. Bousta, A. El Ouali Lalami, M. Lachkar, and A. Farah, "Ultrasound-assisted extraction of phenolic compounds from Moroccan lavandula stoechas L.: optimization using response surface methodology," Journal of Chemistry, vol. 2021, 2021.

[10] S. Chemat, A. Lagha, H. AitAmar, P. V. Bartels, and F. Chemat, "Comparison of conventional and ultrasoundassisted extraction of carvone and limonene from caraway seeds," Flavour and Fragrance Journal, vol. 19, no. 3, pp. 188-195, 2004.

[11] Y. T. Tung, W. C. Chang, P. S. Chen, T. C. Chang, and S. T. Chang, "Ultrasound-assisted extraction of phenolic antioxidants from Acacia confusa flowers and buds," Journal of Separation Science, vol. 34, no. 7, pp. 844-851, 2011.

[12] A. Yahyaoui, G. Rigane, S. Mnif, R. B. Salem, A. Acar, and D. Arslan, "Ultrasound technology parameters: effects on phenolics in olive paste and oil in relation to enzymatic activity," European Journal of Lipid Science and Technology, vol. 121, no. 5, Article ID 1800295, 2019.

[13] J. A. Pino, Y. Aragüez-Fortes, and L. M. Rodríguez, "Optimization of spray-drying parameters for mature acerola powder production," Journal of Raw Materials to Processed Foods, vol. 1, pp. 40-46, 2020.

[14] Y. Ma, X. Ye, Y. Hao, G. Xu, G. Xu, and D. Liu, "Ultrasoundassisted extraction of hesperidin from Penggan (Citrus reticulata) peel," Ultrasonics Sonochemistry, vol. 15, no. 3, pp. 227-232, 2008.

[15] L. Yang, Y.-L. Cao, J.-G. Jiang, Q.-S. Lin, J. Chen, and L. Zhu, "Response surface optimization of ultrasound-assisted flavonoids extraction from the flower of Citrus aurantium L. var. 
amara Engl," Journal of Separation Science, vol. 33, no. 9, pp. 1349-1355, 2010.

[16] K. Ghafoor and Y. H. Choi, "Optimization of ultrasound assisted extraction of phenolic compounds and antioxidants from grape peel through response surface methodology," Journal of the Korean Society for Applied Biological Chemistry, vol. 52, no. 3, pp. 295-300, 2009.

[17] M. H. Alu'datt, I. Alli, K. Ereifej, M. Alhamad, A. R. AlTawaha, and T. Rababah, "Optimisation, characterisation and quantification of phenolic compounds in olive cake," Food Chemistry, vol. 123, no. 1, pp. 117-122, 2010.

[18] F. Rubio-Senent, G. Rodríguez-Gutíerrez, A. Lama-Muñoz, and J. Fernández-Bolaños, "New phenolic compounds hydrothermally extracted from the olive oil byproduct alperujo and their antioxidative activities," Journal of Agricultural and Food Chemistry, vol. 60, no. 5, pp. 1175-1186, 2012.

[19] S. Fan, G. Yang, J. Zhang, J. Li, and B. Bai, "Optimization of ultrasound-assisted extraction using response surface methodology for simultaneous quantitation of six flavonoids in Flos Sophorae Immaturus and antioxidant activity," Molecules, vol. 25, no. 8, Article ID 1767, 2020.

[20] A. Ghasemzadeh and H. Z. Jaafar, "Optimization of reflux conditions for total flavonoid and total phenolic extraction and enhanced antioxidant capacity in pandan (Pandanus amaryllifolius Roxb.) using response surface methodology," Science World Journal, vol. 2014, 2014.

[21] M. Chen, Y. Zhao, and S. Yu, "Optimisation of ultrasonicassisted extraction of phenolic compounds, antioxidants, and anthocyanins from sugar beet molasses," Food Chemistry, vol. 172, pp. 543-550, 2015.

[22] S. Samaram, H. Mirhosseini, C. Tan, C. P. Ghazali, H. M. Bordbar, and A. Serjouie, "Optimisation of ultrasoundassisted extraction of oil from papaya seed by response surface methodology: Oil recovery, radical scavenging antioxidant activity, and oxidation stability." Food Chemistry, vol. 172, pp. 7-17.

[23] A. Ciric, B. Krajnc, D. Heath, and N. Ogrinc, "Response surface methodology and artificial neural network approach for the optimization of ultrasound-assisted extraction of polyphenols from garlic," Food and Chemical Toxicology, vol. 135, Article ID 110976, 2019.

[24] C. S. Dzah, Y. Duan, H. Zhang et al., "The effects of ultrasound assisted extraction on yield, antioxidant, anticancer and antimicrobial activity of polyphenol extracts: a review," Food Bioscience, vol. 35, Article ID 100547, 2020.

[25] N. Yusof, M. S. A. Munaim, and R. Veloo Kutty, "Optimization of total phenolic compounds extracted from propolis by ultrasound-assisted extraction," Chemical Engineering Communications, vol. 208, pp. 564-572, 2020.

[26] A.-S. Zhu, J.-N. Ye, and F.-N. Yan, "Optimization of extraction technology of polysaccharide from foxtail millet using response surface methodology," Chemical Industry and Chemical Engineering Quarterly, vol. 20, no. 4, pp. 579-585, 2014.

[27] H. Mohammadpour, S. M. Sadrameli, F. Eslami, and A. Asoodeh, "Optimization of ultrasound-assisted extraction of Moringa peregrina oil with response surface methodology and comparison with Soxhlet method," Industrial Crops and Products, vol. 131, pp. 106-116, 2019.

[28] B. Vázquez-Rodríguez, J. A. Gutiérrez-Uribe, M. AntunesRicardo, L. Santos-Zea, and L. E. Cruz-Suárez, "Ultrasoundassisted extraction of phlorotannins and polysaccharides from Silvetia compressa (Phaeophyceae)," Journal of Applied Phycology, vol. 32, pp. 1441-1453, 2020.
[29] F. Kougnimon, A. E. DougnonV, H. Bankole, M. Soumanou, and F. Loko, "Propriétés biologiques et pharmacologiques de Terminalia superba Engl. et Diels (Combretaceae): synthèse bibliographique," Algerian Journal of Natural Products, vol. 3, no. 2, pp. 164-176, 2015.

[30] I. A. Mohamed Ahmed, F. Al-Juhaimi, A. R. Adisa et al., "Optimization of ultrasound-assisted extraction of phenolic compounds and antioxidant activity from Argel (Solenostemma argel Hayne) leaves using response surface methodology (RSM)," Journal of Food Science \& Technology, vol. 57, pp. 3071-3080, 2020.

[31] M. Wei, R. Zhao, X. Peng, C. Feng, H. Gu, and L. Yang, "Ultrasound-assisted extraction of taxifolin, diosmin, and quercetin from abies nephrolepis (trautv.) maxim: kinetic and thermodynamic characteristics," Molecules, vol. 25, no. 6, Article ID 1401, 2020.

[32] A. Sonawane, S. Pathak, and R. C. Pradhan, "Bioactive compounds in bael fruit pulp waste: ultrasound-assisted extraction, characterization, modeling, and optimization approaches," Biointerface Research in Applied Chemistry, vol. 11, no. 1, pp. 9318-9334, 2020.

[33] M. d. M. Contreras, A. Lama-Muñoz, F. Espínola, M. Moya, I. Romero, and E. Castro, "Valorization of olive mill leaves through ultrasound-assisted extraction," Food Chemistry, vol. 314, Article ID 126218, 2020.

[34] H. Cui, T. Lu, M. Wang et al., "Flavonoids from morus alba L. Leaves: optimization of extraction by response surface methodology and comprehensive evaluation of their antioxidant, antimicrobial, and inhibition of $\alpha$-amylase activities through analytical hierarchy process," Molecules, vol. 24, no. 13, Article ID 2398, 2019.

[35] Q. D. Do, A. E. Angkawijaya, P. L. Tran-Nguyen et al., "Effect of extraction solvent on total phenol content, total flavonoid content, and antioxidant activity of Limnophila aromatica," Journal of Food and Drug Analysis, vol. 22, no. 3, pp. 296-302, 2014.

[36] A. A. Kamarudin, N. M. Esa, N. Saad, N. H. Sayuti, and N. A. Razak, "Heat assisted extraction of phenolic compounds from Eleutherine bulbosa (Mill.) bulb and its bioactive profiles using response surface methodology," Industrial Crops and Products, vol. 144, Article ID 112064, 2020.

[37] G. Rigane, R. B. Salem, S. Sayadi, and M. Bouaziz, "Phenolic composition, isolation, and structure of a new deoxyloganic acid derivative from dhokar and gemri-dhokar olive cultivars," Journal of Food Science, vol. 76, no. 7, pp. C965-C973, 2011.

[38] G. Rigane, S. B. Younes, H. Ghazghazi, and R. Ben Salem, "Investigation into the biological activities and chemical composition of Calendula officinalis L. growing in Tunisia," International Food Research Journal, vol. 20, no. 6, pp. 3001-3007, 2013.

[39] M. Boukhris, M. S. J. Simmonds, S. Sayadi, and M. Bouaziz, "Chemical composition and biological activities of polar extracts and essential oil of rose-scented Geranium, Pelargonium graveolens," Phytotherapy Research, vol. 27, no. 8, pp. 1206-1213, 2013.

[40] S. A. O. Santos, J. J. Villaverde, C. S. R. Freire, M. R. M. Domingues, C. P. Neto, and A. J. D. Silvestre, "Phenolic composition and antioxidant activity of Eucalyptus grandis, E. urograndis (E. grandis $\times$ E. urophylla) and E. maidenii bark extracts," Industrial Crops and Products, vol. 39, pp. 120-127, 2012.

[41] E. Al-Sayed, A.-N. Singab, N. Ayoub, O. Martiskainen, J. Sinkkonen, and K. Pihlaja, "HPLC-PDA-ESI-MS/MS 
profiling and chemopreventive potential of Eucalyptus gomphocephala DC," Food Chemistry, vol. 133, no. 3, pp. 1017-1024, 2012.

[42] G. Vázquez, J. Santos, M. S. Freire, G. Antorrena, and J. González-Álvarez, "Extraction of antioxidants from eucalyptus (Eucalyptus globulus) bark," Wood Science and Technology, vol. 46, no. 1-3, pp. 443-457, 2012. 